\title{
CORRESPONDENCE
}

\section{Aneurysms of the Ascending Aorta}

by Dr. med. Daniel Lavall, Prof. Dr. med. Hans-Joachim Schäfers, Prof. Dr. med. Michael Böhm, Prof. Dr. med. Ulrich Laufs in volume 13/2012

\section{Additional Criterion}

Lavall and colleagues deserve thanks for their excellent review article (1). The American guidelines (2) include as an additional criterion that any (one might wish to amend: greater than trivial) increase in distal aortic diameter should be categorized as a dilatation, independently of the absolute numeric value. If this was kept in mind by echocardiographers and attention as well as orientation of the transducer were routinely directed slightly distally, then in our own experience, they would find far more cases of (mostly hypertensive) aortic dilatation in an unselected patient cohort in a cardiology referral practice than has been assumed so far, especially in women and people of short stature.

As far as the comparison of ultrasound and other values is concerned, I wish to point out that the values obtained by means of echocardiography (mostly the internal diameter) and computed tomography/magnetic resonance scanning (both the internal or external diameter are in use [2,3]) are not directly comparable and are furthermore subject to more than trivial intraindividual variation over the course of time.

Assessment in the individual case is further complicated by the fact that the normal diameter of the aorta depends on a person's age (4). Defining the proper time for surgery is additionally hampered by the fact that the indication for surgery is graded according to absolute diameters (45-50-55-60 $\mathrm{mm})$, whereas the normal ranges are sensibly indexed according to body surface area. It would be highly desirable for the medical specialty societies to establish clarity by relating the limits to the body surface area rather than absolute measurements of diameter.

DOI: 10.3238/arztebl.2012.0504a

\section{REFERENCES}

1. Lavall D, Schäfers HJ, Böhm M, Laufs U: Aneurysms of the ascending aorta. Dtsch Arztebl Int 2012; 109(13): 227-33.

2. Hiratzka LF, et al.: ACCF/AHA/AATS/ACR/ASA/SCA/SCAI/SIR/STS/ SVM guidelines for the diagnosis and management of patients with aortic disease. Circulation 2010; 121: e266-e369.

3. Elefteriades JA, et al.: Thoracic aortic aneurysm. J Am Coll Cardiol 2010; 55: 841-57.

4. Hannuksela M, et al.: Thoracic aorta dilated or not? Scand Cardiovasc J 2006; 40: 175

Dr. med. Michael Kuklinski

Internist/Kardiologe, Aalen

praxis@kardiologie-aalen.de

Conflict of interest statement

Dr Kuklinski has received a lecture honorarium from Novartis.

\section{Addendum}

Lavall and colleagues, in their review article on aneurysms of the ascending aorta (1), point out the importance of distinguishing the genotypes for the purposes of differential diagnosis of Loeys-Dietz syndrome type 2 and vascular Ehlers-Danlos syndrome, as this affects the prognosis and determines the further management. We wish to add the following: distinguishing between the phenotypes of Marfan syndrome and Loeys-Dietz syndrome is sometimes not possible, especially when the disease is first diagnosed and in adult patients.

We recently conducted a systematic study (2) in which we confirmed and quantified earlier observations of our own (3) and those of other authors (for example [4]). In 7 of 124 patients who, according to their clinical criteria, had Marfan syndrome, genetic investigations actually yielded a diagnosis of LoeysDietz syndrome. This is of utmost importance for the management of these patients, since-as Lavall et al point out - in patients with Loeys-Dietz syndrome, an indication for elective aortic surgery can be defined from a diameter of $40 \mathrm{~mm}$ or greater, not of $45 \mathrm{~mm}$ or $50 \mathrm{~mm}$, such as in classic Marfan syndrome. Furthermore, genetically determined aortic aneurysms may occur even without or with very mild stigmata of a syndromal disorder and may still be caused by mutations in the FBN1-, TGFBR1-, or TGFBR2-gene. We therefore think that genotype diagnosis is generally indicated in suspected cases of genetically determined aortic aneurysms.

DOI: 10.3238/arztebl.2012.0504b

\section{REFERENCES}

1. Lavall D, Schäfers HJ, Böhm M, Laufs U: Aneurysms of the ascending aorta. Dtsch Arztebl Int 2012; 109(13): 227-33.

2. Sheikhzadeh S, Kade C, Keyser B, et al.: Analysis of phenotype and genotype information for the diagnosis of Marfan syndrome. Clin Genet 2011; [Epub ahead of print]

3. Singh KK, Rommel K, Mishra A, et al.: TGFBR1 and TGFBR2 mutations in patients with features of Marfan syndrome and Loeys-Dietz syndrome. Hum Mutat 2006; 27: 770-7.

4. Mizuguchi T, Collod-Beroud G, Akiyama T, et al.: Heterozygous TGFBR2 mutations in Marfan syndrome. Nat Genet 2004; 36: $855-60$.

Prof. Dr. med. Jörg Schmidtke

Institut für Humangenetik, Medizinische Hochschule Hannover

Schmidtke.Joerg@mh-hannover.de

Prof. Dr. med. Yskert von Kodolitsch

Universitäres Herzzentrum Hamburg

kodolitsch@uke.de

\section{Conflict of interest statemen}

Professor von Kodolitsch has been reimbursed delegate fees for a furthe medical educational event from a geneticist in private practice.

Professor Schmidtke declares that no conflict of interest exists . 


\section{In Reply:}

It would certainly make perfect sense to consider a patient's body height when assessing aortic diameters (1), as suggested by Kuklinski. Simple and practical indexing to the body surface area helps individualized assessment of aortic dilatation. For example, in patients of short stature the risk of complications may be underestimated on the basis of considering the absolute diameter only. Since only few clinical data for indexing exist, this has thus far not been included in any guidelines. Defining normal values and threshold values need to be defined by means of clinical studies. We gave pointers for a possible practical approach that is based on the currently available evidence (1).

The lacking standardization of how the aortic diameter is measured, as raised by Kuklinski, is an unsolved problem since several existing guidelines provide different recommendations $(2,3)$. The current US guidelines recommend measuring the internal diameter by using echocardiography and the external diameter by using CT/MRI scanning (2). Echocardiography is restricted by the limited visibility of the ascending aorta and the variability of the diameter with the imaging plane. CR and MRI investigations allow for better reproducibility, but it has to be borne in mind that the diameter varies between systole and diastole. In younger patients with repeated investigations, MRI is the investigation of choice because of the lack of exposure to radiation (1).

The prognosis of aneurysms of the ascending aorta is determined not only by the diameter but, crucially, also by other risk factors, progression, and etiology (1). We agree with Schmidtke and von Kodolitsch that the care of patients with congenital disorders of the connective tissues is an important topic. In spite of substantial increase to what is known about the subject over the past decade, many details of the genotype and phenotype changes remain unknown. Currently we can therefore make only tentative recommendations for managing patients with congenital connective tissue disorders. Screening of the ascending aorta is recommended for all first-degree relatives of patients with congenital aortic disorders - that is, connective tissue disorders, bicuspid aortic valve, etc (2). Genetic diagnosis is indicated if it is of therapeutic relevance for the patient-for example, the intensity of monitoring, the timing of potential aortic replacement, or if they are planning to have children.

In conclusion, further studies of aneurysms of the ascending aorta are urgently needed.

DOI: 10.3238/arztebl.2012.0505

\section{REFERENCES}

1. Lavall D, Schäfers HJ, Böhm M, Laufs U: Aneurysms of the ascending aorta. Dtsch Arztebl Int 2012; 109(13): 227-33.

2. Hiratzka LF, et al.: ACCF/AHA/AATS/ACR/ASA/SCA/SCAI/SIR/STS/ SVM guidelines for the diagnosis and management of patients with aortic disease. Circulation 2010; 121: e266-e369.

3. Vahanian A, Baumgartner H, Bax J, et al.: Guidelines on the management of valvular heart disease: The Task Force on the Management of Valvular Heart Disease of the European Society of Cardiology. Eur Heart J 2007; 28: 230-68.

Dr. med. Daniel Lavall

Prof. Dr. med. Michael Böhm

Prof. Dr. med. Ulrich Laufs

Klinik für Innere Medizin III - Kardiologie, Angiologie und

Internistische Intensivmedizin

Universitätsklinik des Saarlandes, Homburg/Saar

daniel.lavall@uks.eu

Prof. Dr. med. Hans-Joachim Schäfers

Klinik für Thorax- und Herz-Gefäßchirurgie, Universitätsklinik des Saarlandes, Homburg/Saar

Conflict of interest statement

The authors declare that no conflict of interest exists

\section{Erratum}

In issue 24, dated 15 June, of Deutsches Ärzteblatt, an editorial error occurred in a reader's letter that led to the author's name being incorrect and the affiliation and declaration of competing interests being omitted. Dr rer nat Siegfried Throm responded to the original article entitled "New Drugs: Evidence Relating to Their Therapeutic Value After Introduction to the Market." He is managing director research, development, innovation at the Verband Forschender Arzneimittelhersteller e.V. (Research-Based Pharmaceutical Companies reg. assoc.). 